\title{
Temporal contrast sensitivity: A potential parameter for glaucoma progression, especially in advanced stages
}

\author{
Pia V. Rutrecht ${ }^{1 \dagger}$, Katharina Brehmer ${ }^{1 \dagger}$, Jan Kremers ${ }^{1,2}$, Folkert K. Horn', \\ Anselm G.M. Jünemann, Bettina Hohberger ${ }^{1}$ \\ 'Department of Ophthalmology and Eye Hospital, Friedrich-Alexander-University Erlangen-Nuremberg (FAU), Erlangen, Germany \\ ${ }^{2}$ School of Life Sciences, University of Bradford, Bradford, West Yorkshire, United Kingdom \\ ${ }^{3}$ Department of Ophthalmology, University of Rostock, Rostock, Germany \\ ${ }^{t}$ The present work was performed in fulfilment of the requirements for obtaining the degree Dr. med. \\ This paper was presented as a poster at the DOG (German Ophthalmological Society) in Berlin on 21.09.2013.
}

\begin{abstract}
INTRODUCTION. Previously it could be shown that temporal contrast sensitivity is affected by glaucoma and maximally influenced after $25-\mathrm{Hz}$ adaptation in normals. This study investigated different kinds of $25-\mathrm{Hz}$ temporal contrast adaptation on TCS in patients with ocular hypertension, preperimetric primary open-angle glaucoma, and perimetric open-angle glaucoma. Additionally, correlations of measured data with parameters of glaucoma diagnostic were done and assessed for the potential use of TCS as a parameter for glaucoma progression.

MATERIALS AND METHODS. One hundred and four subjects were included: 44 normals, 14 ocular hypertensions, 11 preperimetric primary open-angle glaucomas, and 35 perimetric open-angle glaucomas. Using the Erlangen Flicker Test, temporal contrast sensitivity was measured without adaptation, after pre-adaptation and after pre- and re-adaptations at $25 \mathrm{~Hz}$. Reliability analyses were done.

RESULTS. All test strategies showed high reliability ( $\alpha$-Cronbach's $>0.86$ ). In normals, age-dependency of temporal contrast sensitivity without adaptation $(\mathrm{p}=0.052)$ and after pre- and re-adaptation $(\mathrm{p}=0.008)$ was observed. Temporal contrast sensitivity is significantly reduced after pre-adaptation for all subjects $(\mathrm{p}<0.001)$. Reduction of temporal contrast sensitivity after pre- and re-adaptations was significant in all groups $(\mathrm{p}<0.001)$, but it was smaller than after single pre-adaptation $(\mathrm{p}<0.001)$. Temporal contrast sensitivity without adaptation was significantly reduced in patients with perimetric glaucoma $(\mathrm{p}=0.040)$ but not in patients with ocular hypertension and preperimetric glaucoma. Correlation analyses yielded a significant correlation between temporal contrast sensitivity without adaptation and mean defect $(\mathrm{p}=0.003, \mathrm{r}=-0.329)$, loss variance $(\mathrm{p}=0.027, \mathrm{r}=-0.256)$, and retinal nerve fibre layer thickness $(\mathrm{p}<0.001, \mathrm{r}=0.413)$ for all subjects and between temporal contrast sensitivity after pre-adaptation and mean defect $(\mathrm{p}=0.045, \mathrm{r}=-0.239)$.

CONCLUSIONS. Temporal contrast sensitivity seems to be affected in perimetric glaucoma with an overall reduction after adaptation. Significant correlations of temporal contrast sensitivity with perimetric and morphologic parameters offer new aspects of its potential use as a glaucoma progressions marker, especially in advanced stages when perimetric diagnosis is limited.
\end{abstract}

KEY WORDS: glaucoma, temporal contrast sensitivity, adaptation, Erlangen Flicker Test

Ophthalmol J 2016; Vol. 1, No. 1, 10-17 


\section{INTRODUCTION}

Glaucoma, as a neurodegenerative disease, results in an irreversible loss of visual field. Thus, parameters monitoring progression are of interest in the management of glaucoma therapy. Up to now, perimetric follow ups and structural analysis of the optic nerve are used in clinical everyday life. Temporal contrast sensitivity (TCS) as well as contrast adaptation to flickering stimuli were found to be reduced in diseases affecting ganglion cells and optic nerve structures. Therefore, TCS was suggested as an early and sensitive diagnostic tool for glaucoma [1-9].

So far only correlations of TCS with perimetric mean defect and papillometric alterations of the neuroretinal rim area were analysed, but not with newer parameters (e.g. retinal nerve fibre layer thickness, loss of variance). Analysis of these correlations could provide new aspects for TCS as a potential marker for glaucoma progression.

Previously it was shown that using the modified Erlangen Flicker Test, TCS is maximally affected after adaptation at $25 \mathrm{~Hz}$ in normals, similar to the frequency of maximal sensitivity [1]. Therefore, this test set-up was suggested to affect the function of luminance channel $[1,3,5]$, which is probably based on activity of the magnocellular retino-geniculate pathway and displays a maximum sensitivity to $20-30 \mathrm{~Hz}$ frequencies under photopic conditions [10]. It is assumed that $25 \mathrm{~Hz}$ temporal contrast adaptation originates mainly in magnocellular structures. This hypothesis is also supported by previous data showing that especially magnocellular cells of the lateral geniculate nucleus (LGN) display luminance contrast adaptation $[11,12]$. These findings suggest that the Erlangen Flicker Test is potentially useful for diagnosis and monitoring of inner retinal diseases like glaucoma.

Adaptation is a common mechanism in sensory systems in order to protect against overstimulation and to remain sensitive under different natural conditions. In visual systems, adaptation can be found in retinal as well as in higher cortical structures [13-20]. As a neuronal mechanism, contrast adaptation (either spatial or temporal) causes reduced contrast sensitivity after high-contrast stimuli presentation [21,22]. Involvement of at least two independent channels has been proposed: a low frequency channel (peak: 1-2 Hz) with cortical origin and a high frequency channel (peak: 8-12 Hz) possibly with subcortical origin [23]. A third channel has been described [24]. Previously, TCS without adaptation was examined in glaucoma patients $[5,25,26]$. However, until today no data on alterations of TCS after contrast adaptations are available in glaucoma.

In this study we investigated different types of $25 \mathrm{~Hz}$ full-field adaptation on TCS in normal subjects, patients with ocular hypertension $(\mathrm{OHT})$, preperimetric primary open-angle glaucoma (POAG), and perimetric open-angle glaucoma (OAG). Additionally, we analysed correlations of TCS ( \pm adaptation) with specific parameters of glaucoma diagnostics and assessed its potential value as a parameter for glaucoma progression.

Parts of this study were presented at the DOG (German Ophthalmologic Society) conference in 2013.

\section{MATERIALS AND METHODS RECRUITIMENT PROCESS}

One hundred and four subjects were recruited from patients and staff of the Department of Ophthalmology and Eye Hospital, Friedrich-Alexander-University of Erlangen-Nürnberg (FAU), as well as from the Erlangen Glaucoma Registry (EGR; ClinicalTrials.gov Identifier: NCT00494923; ISSN 2191-5008, CS-2011).

All probands were examined by slit-lamp biomicroscopy and tonometry. Standard white-on-white full-field perimetry (Octopus 500, G1 protocol, Interzeag, Schlieren, Switzerland) defined the parameters' mean defect (MD) and regular loss variance (LV), and standard deviation of MD. A normal visual field showed:

- MD of 2.8 or less;

- less than three adjacent test points on the pattern deviation map with a probability of less than 5\%;

- less than two adjacent test points on the pattern deviation map with a probability of less than $1 \%$; whereas visual field defects had:

- MD greater than 2.8;

- three or more adjacent test points on the pattern deviation map with a probability of less than $5 \%$;

- two or more adjacent test points on the pattern deviation map with a probability of less than $1 \%$.

The subjects received measurements of global retinal nerve fibre layer (RNFL) of macula and optic disc using Spectralis ${ }^{\circledR}$ OCT (Version 1.9.10.0, Heidelberg Engineering, Heidelberg, Germany). All patients' lenses were classified based on the lens opacities classification system III (LOCS III) [27]. Further exclusion criteria were visual acuity less than 


\begin{tabular}{|c|c|c|c|c|}
\hline Variable & Normals & Ocular hypertension & $\begin{array}{c}\text { Preperimetric } \\
\text { open-angle glaucoma }\end{array}$ & $\begin{array}{c}\text { Perimetric } \\
\text { open-angle glaucoma }\end{array}$ \\
\hline Age (years) & $50.50 \pm 12.93(44)$ & $49.50 \pm 13.03(14)$ & $56.73 \pm 8.87(11)$ & $61.00 \pm 8.57(35)$ \\
\hline Gender $(F, M)$ & $28 \mathrm{~F}, 16 \mathrm{M}$ & $7 F, 7 \mathrm{M}$ & $5 \mathrm{~F}, 6 \mathrm{M}$ & $21 \mathrm{~F}, 14 \mathrm{M}$ \\
\hline Visual acuity & $0.96 \pm 0.11(44)$ & $0.99 \pm 0.05(14)$ & $1.02 \pm 0.08(11)$ & $0.89 \pm 0.17(35)$ \\
\hline Pachymetry & $550.57 \pm 34.57(42)$ & $575.93 \pm 37.63(14)$ & $540.27 \pm 45.85(11)$ & $525.43 \pm 36.36(35)$ \\
\hline Mean defect & $1.15 \pm 0.77(44)$ & $0.81 \pm 0.79(14)$ & $0.72 \pm 0.99(11)$ & $6.25 \pm 2.80(35)$ \\
\hline Loss variance & $4.85 \pm 4.30(44)$ & $3.56 \pm 1.45(14)$ & $3.55 \pm 1.70(11)$ & $35.75 \pm 32.75(35)$ \\
\hline Retinal nerve fibre layer & $97.64 \pm 9.26(44)$ & $96.00 \pm 12.07(14)$ & $84.18 \pm 17.40(11)$ & $68.66 \pm 13.01(35)$ \\
\hline
\end{tabular}

$\mathrm{F}$ - female; $\mathrm{M}$ - male

0.8 , age less than 18 years, neurological, psychiatric, or psychosomatic diseases, systemic diseases with possible eye involvement (like diabetes mellitus or arterial hypertension), any other eye disease except OAG and OHT, and ophthalmological surgeries. Secondary open-angle glaucoma, subjects taking any medication affecting central nervous system as well as hyperopic and myopic eyes greater than $\pm 6 \mathrm{dpt}$ were excluded. If both eyes failed to meet the exclusion criteria, the eye with best corrected visual acuity was chosen. Further demographic data are shown in Table 1. Informed consent was obtained from each subject before joining the study. The study was conducted in accordance with the tenets of the Declaration of Helsinki and was approved by the Local Ethics Committee (176_12B).

\section{SUBJECTS}

In total 104 subjects were included in the study: 44 normals, 14 patients with OHT, 11 patients with preperimetric $\mathrm{POAG}$, and 35 perimetric OAG subjects (13 normal tension glaucomas (NTG), 22 POAGs). Only patients with perimetric OAG had visual field defects. All glaucoma patients showed an altered optic disc classified after Jonas [28, 29].

\section{METHODS}

The experimental test set-up has been described before $[1,5]$. Briefly, the modified version of the Erlangen Flicker Test uses a full-field flicker bowl (Ganzfeld Q450 F, software: Retiport ${ }^{\circ}$, Roland Consult, Brandenburg, Germany) with white light-emitting diodes (LEDs), presenting a sinusoidal luminance modulation. Two spatially homogeneous, temporally modulated stimuli $(25 \mathrm{~Hz}$ temporal frequency each) were presented: a $100 \%$ contrast adaptation stimulus and a test stimulus of variable contrast. The mean luminance of test and adapting stimuli was $49.5 \mathrm{~cd} / \mathrm{m}^{2}$. The threshold contrast $(\mathrm{K})$ for flicker detection of the test stimulus was determined. TCS was defined as inverse of K:

$$
\operatorname{TCS}=1 / K=1 /\left(100 \% \cdot\left(I_{\max }-I_{\min }\right) /\left(I_{\max }+I_{\min }\right)\right)
$$

TCS - temporal contrast sensitivity;

$\mathrm{K}$ - temporal contrast at detection threshold (\%);

$\mathrm{I}_{\max }$ - maximal intensity of modulation;

$\mathrm{I}_{\min }$ - minimal intensity of modulation.

TCS values were age-corrected using a linear regression method based on TCS measurements without adaptation, because these reflect results without any adaptation influence. For analysis, the decimal logarithms of TCSs were calculated for normal distribution obtainment. Using the following three different psychophysical testing conditions, TCS was determined. A test run prior to each strategy was included to prevent learning effects.

\section{MEASUREMENTS OF TCS WITHOUT ANY TEMPORAL CONTRAST ADAPTATION}

Before test start, examples of test stimuli were shown in order to familiarise the test person with the test procedure. Subsequently, starting at sub-threshold values, contrast was slowly manually increased in $0.05 \%$-contrast steps until flicker detection. Then, contrast was increased to supra-threshold values and slowly manually decreased in $0.05 \%$-steps until flicker detection vanished. This procedure was repeated three times (Fig. 1). The first two threshold contrasts $(\mathrm{t} 1, \mathrm{t} 2)$ were excluded from analysis. The mean of the remaining four threshold contrasts (T3 - T6) were statistically analysed. 


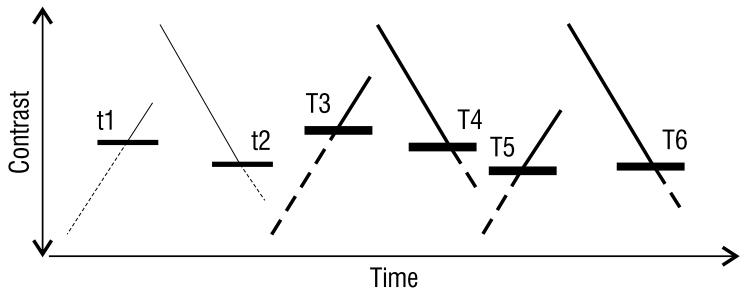

FIGURE 1. Test strategy for measurements of temporal contrast sensitivity without any temporal contrast adaptation. First, contrast was slowly increased until the subject could identify the flickering test stimulus. Then supra-threshold contrast was displayed followed by a decrease of contrast until the test stimulus could not be detected. The corresponding contrast threshold was calculated as the mean of T3-T6. The two first contrast thresholds $\mathrm{t} 1$ and $\mathrm{t} 2$ were excluded from further analysis to avoid artefacts caused by learning effects

\section{MEASUREMENTS OF TCS AFTER PRE-ADAPTATION AT $25 \mathrm{HZ}$}

Each subject was adapted to a $100 \%$ contrast adaptation stimulus for 15 seconds (s). Then the test stimulus was presented: Initial contrast was $0.39 \%$, stepwise increased in $1-\mathrm{dB}$ steps every 0.5 seconds, until the subject indicated stimulus detection by pressing a button. This procedure was repeated four times without interruption (Fig. 2). The first trial (u1) was excluded from further analysis. The mean of the remaining three threshold contrasts (U2-U4) were used to determine threshold contrasts.

\section{MEASUREMENTS OF TCS AFTER PRE- AND RE-ADAPTATIONS AT $25 \mathrm{HZ}$}

Each subject was pre-adapted to a stimulus of $100 \%$ contrast for 15 seconds. Subsequently, test stimulus was displayed starting at either $3 \%$ or $5 \%$ contrast. Test and adaptation stimuli were alternately presented (five seconds each) for continuous re-adaptation. Contrast was increased in 1-dB steps until the subject indicated flicker perception by pressing a button followed by a decrease of the test contrast by $3 \mathrm{~dB}$. This procedure was repeated four times (Fig. 3) with two cycles conducted. The first trial in each cycle was a test run (s1). Threshold contrast was defined as the mean of S2, S3, and S4 of each of the two cycles.

\section{RELIABILITY ANALYSIS}

For reliability analysis, five subjects were examined at all three test conditions three times on one day for short-term inter-test reliability. For longterm inter-test reliability the thresholds were measured in three different sessions with a few weeks' interval. $\alpha$-Cronbach's values were evaluated.

\section{STATISTICAL ANALYSIS}

Statistical analysis was performed using t-tests for independent groups and correlation analysis. A Bonferroni correction for multiple testing was conducted. Analysis was performed using SPSS (V21.0).

\section{RESULTS \\ RELIABILITY ANALYSIS}

TCS measurements without adaptation showed a short-term reliability with an $\alpha$-Cronbach's value of 0.958 and a long-term reliability with an $\alpha$-Cron-

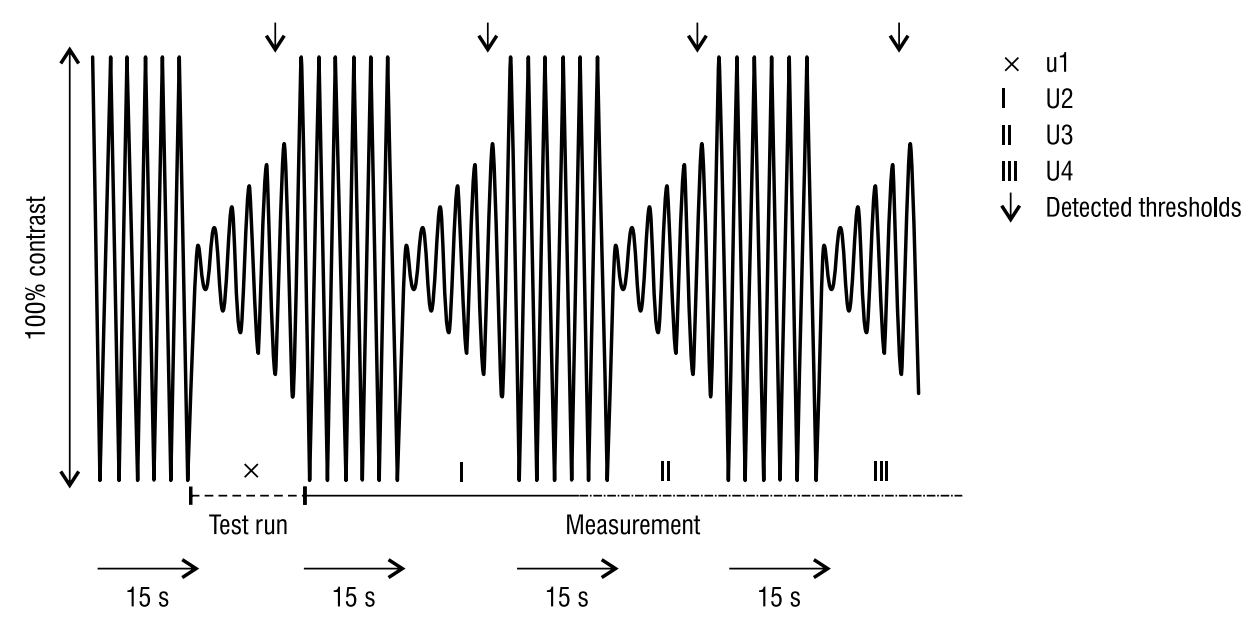

FIGURE 2. Test strategy for measurements of temporal contrast sensitivity after pre-adaptation at $25 \mathrm{~Hz}$. The subject was adapted to a $25 \mathrm{~Hz}$ adaptation stimulus at $100 \%$ contrast for 15 seconds. Then the test stimulus was displayed at sub-threshold contrast of $0.39 \%$ and stepwise increased by $1 \mathrm{~dB}$ every $500 \mathrm{~ms}$ until stimulus detection was indicated by pressing a button. This procedure was repeated four times with the first cycle (u1) being a test run. The mean of the other three measured contrast thresholds (U2-U4), marked by arrows, was defined as temporal contrast adaptation after single flicker adaptation 


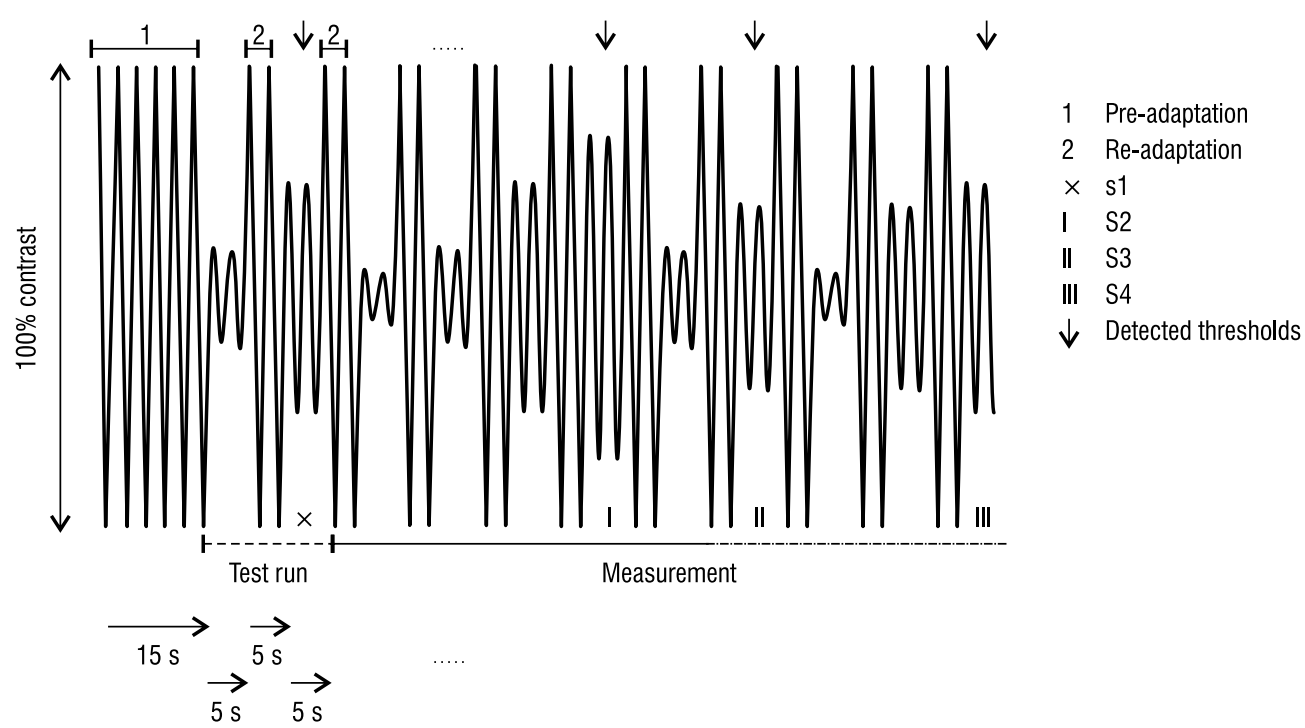

FIGURE 3. Test strategy for measurements of temporal contrast sensitivity after pre- and re-adaptations at $25 \mathrm{~Hz}$. First, a $25 \mathrm{~Hz}$ adaptation stimulus (100\% contrast, 15 seconds) was presented. Then, alternately cycles of test stimulus, starting either at $3 \%$ or at $5 \%$ contrast, and adaptation stimulus were performed. The subject was instructed to press a button if the test stimulus was seen. If no flicker was detected, the contrast of the test stimulus was increased in 1-dB steps after each next re-adapting phase until it was detected by the subject. If the test stimulus could be detected, contrast was decreased by $3 \mathrm{~dB}$. The four contrast thresholds distinguished by the patient in one trial were defined by S1-S4. $\mathbf{s} 1$ was a test run. The mean of S2-S4, marked by arrows and measured twice, defined TCS after pre- and re-adaptation
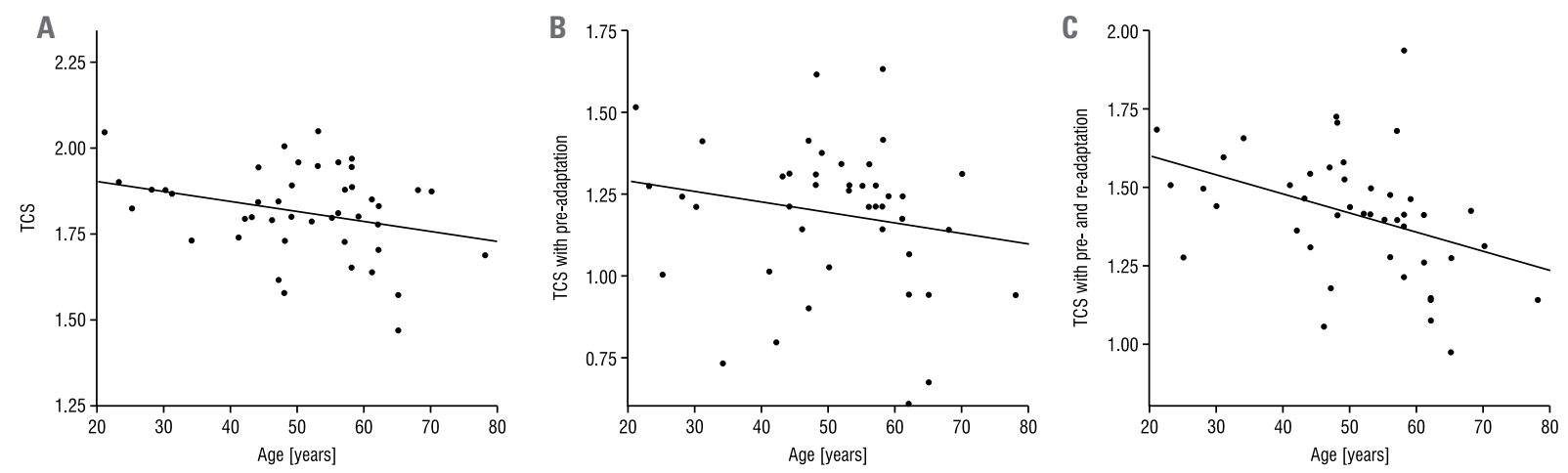

FIGURE 4. Temporal contrast sensitivity plotted as a function of age for all three test strategies. Temporal contrast sensitivity decreased with increasing age for all three test strategies. A. Scatterplot for temporal contrast sensitivity without adaptation: temporal contrast sensitivity decreases in steps of 0.03 log units every 10 years; B. Scatterplot for temporal contrast sensitivity with pre-adaptation: temporal contrast sensitivity decreases in steps of 0.03 log units every 10 years; C. Scatterplot for temporal contrast sensitivity with pre- and re-adaptation: temporal contrast sensitivity decreases in steps of 0.06 log units every 10 years

bach's value of 0.939 . Also, TCSs after pre-adaptation yielded high short- $(\alpha$-Cronbach's value $=0.860)$ and long-term $(\alpha$-Cronbach's value $=0.930)$ inter-test reliabilities. Finally, the $\alpha$-Cronbach's values for TCSs after pre- and re-adaptations were 0.989 for shortand 0.916 for long-term reliability. In conclusion, for all three test conditions high short- and long-term reliabilities were found.

\section{AGE-DEPENDENCY OF TCS}

In normal subjects, linear regression revealed for the whole studied age range a moderate TCS decrease of $0.03 \mathrm{~dB}$ every decade without adaptation ( $\mathrm{p}=0.052)$ (Fig. 4A) as well as a decrease of $0.06 \mathrm{~dB}$ every decade after pre- and re-adaptation $(\mathrm{p}=0.008)$ (Fig. 4C). For TCS after pre-adaptation no significant age correlation was found although a negative trend was observed $(\mathrm{p}=0.237)$ (Fig. $4 \mathrm{~B})$.

\section{TCS WITHOUT ADAPTATION}

TCS without adaptation is significantly reduced in patients with perimetric OAG compared to normal subjects ( $p=0.040)$ (Fig. 5), but not in patients with OHT and preperimetric POAG $(\mathrm{p}>0.05)$. 


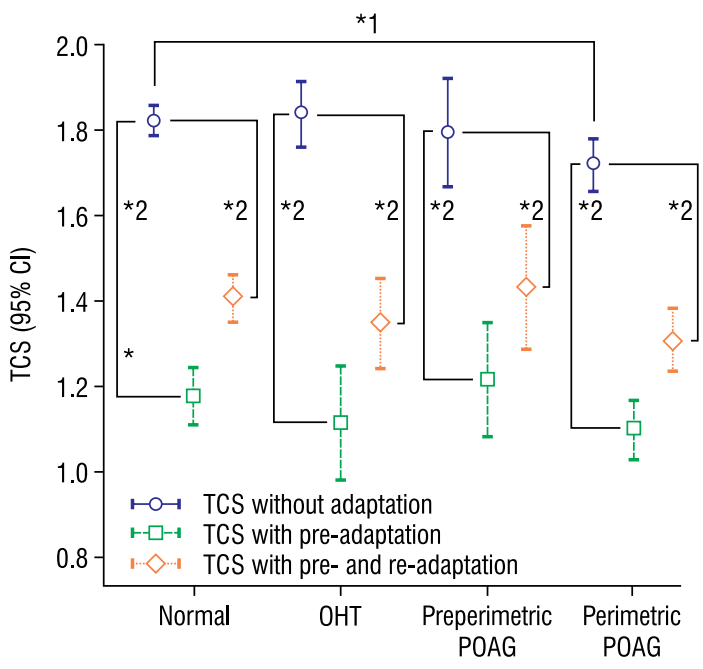

FIGURE 5. Temporal contrast sensitivity (TCS) in different subject groups: TCS without adaptation (open circles, straight line), after a single pre-adaptation (open squares, dashed line), and after pre- and re-adaptation (open diamonds, dotted line) for all four groups [normals, ocular hypertension (OHT), preperimetric primary open-angle glaucoma (POAG), perimetric open-angle glaucoma (OAG)]. A significant reduction of TCS without adaptation was found in perimetric OAGs compared to normal subjects $\left(p=0.009^{* 1}\right)$. In all groups, TCS was significantly reduced after pre- as well as after pre- and re-adaptations $\left(p<0.001^{* 2}\right)$. The reduction was larger when a single pre-adaptation was used

\section{TCS AFTER ADAPTATION TO $25 \mathrm{HZ}$}

TCS after $25 \mathrm{~Hz}$ pre-adaptation was reduced in all subjects [1]. Additionally, TCS after $25 \mathrm{~Hz}$ preand re-adaptations was significantly decreased in all tested groups ( $\mathrm{p}<0.001$ ) (Fig. 5). However, a single pre-adaptation resulted in a significantly larger TCS reduction than pre- and re-adaptations $(\mathrm{p}<0.001)$. No significant differences of TCS were found after pre-adaptation or after pre- and re-adaptations in patients compared to normals $(\mathrm{p}>0.05)$. No significant differences were found between NTG and POAG patients for all test strategies ( $p>0.05)$.

\section{CORRELATIONS OF STANDARD PERIMETRIC AND MORPHOLOGIC PARAMETERS WITH THE DIFFERENT TCS TEST STRATEGIES}

Since measurements of the TCSs were performed under full-field conditions in this study, the parameters MD, LV, and global RNFL were used for statistical analysis. A significant correlation was found between MD and values of TCS without adaptation $(\mathrm{p}=0.003, \mathrm{r}=-0.329)$ as well as TCS after pre-adaptation $(\mathrm{p}=0.045, \mathrm{r}=-0.239)$. TCS after pre- and re-adaptations did not correlate with MD. TCS without adaptation correlated with LV $(\mathrm{p}=0.027, \mathrm{r}=-0.256)$ as well as with global RNFL thickness ( $\mathrm{p}<0.001, \mathrm{r}=0.413)$. These correlations disappeared after adaptation.

\section{DISCUSSION}

This study investigated TCS with and without different kinds of adaptation at $25 \mathrm{~Hz}$ in patients with OHT, and preperimetric and perimetric glaucoma compared to normals and analysed potential correlations of TCS with perimetric and morphologic parameters.

TCS, measured by the Erlangen Flicker Test, seems to reflect in particular magnocellular retinal ganglion cell (RGC) activity [3]. Based on the theory of reduced redundancy, testing these specific neurons after adaptation is of interest in glaucoma diagnosis [30].

Confirming previous data, a significant correlation was found between TCS and age [9, 25, 31-34]. TCS without adaptation showed a significant correlation with standard perimetric parameter MD, agreeing with previous studies $[6,7,26,35,36]$. As a new aspect, TCS without adaptation correlated significantly with LV. Previously, analysis of glaucoma suspects of the EGR showed a prognostic value of increasing square root of loss variance (sLV) for conversion from preperimetric to perimetric glaucoma, emphasising the importance of investigations on $\mathrm{LV}$ in glaucoma diagnosis (Hohberger B, Horn F, Jünemann A, Lämmer R. Longitudinal analysis of glaucoma suspects from the Erlangen glaucoma registry (ERG): Influence of neuroretinal rim area and visual field indices on progression. Meeting abstract ARVO 2013). Further on, morphologic data of the global RNFL correlated significantly with TCS without adaptation. Until now, all previous studies correlated TCS with papillometric alterations of the neuroretinal rim area $[26,36]$. Considering these results, reduced area of neuroretinal rim, measured by OCT, and elevated sLV may be considered as indicators for glaucoma progression - both significantly correlated with TCS. Including adaptation, TCS after pre-adaptation correlated significantly only with MD. Therefore, adaptation mechanisms do not seem to be strongly affected by glaucoma progression. However, TCS without adaptation interacts with MD, LV, and global RNFL values and can be used as a potential progression marker for glaucoma monitoring when perimetric diagnosis is limited. Using the Erlangen Flicker Test for TCS measurement performance is beneficial because no 
fixation, critically especially in advanced glauco$\mathrm{ma}$, is necessary. Under full-field conditions defined visual field defects cannot be localised. However, local damages seem to be associated with general impaired ability of flicker detection [7]. Additionally, this test set-up is not influenced by lens density as many older glaucoma patients suffer from cataracts, influencing perimetry and therefore limiting the diagnostic value of standard perimetry [37].

In perimetric glaucoma patients TCS without adaptation showed significantly reduced results compared to normals. Unlike previous studies, there was no significant reduction of TCS in patients with $\mathrm{OHT}$ and preperimetric glaucoma $[2,36,38,39]$. One explanation can potentially be found in the light sources: Some previous studies used a xenon arc lamp, whereas the Erlangen Flicker Test uses LEDs $[2,36]$. Possibly, the different spectral light distribution is relevant. Further on, different light intensities could potentially influence TCS results: The mean luminance of test and adapting stimuli in the present test set-up was $49.5 \mathrm{~cd} / \mathrm{m}^{2}$ to avoid adjustments of pupil size to different light intensities. Also, changing flicker frequencies might achieve different results [38, 39].

TCS after single pre-adaptation as well as in combination with re-adaptations were clearly reduced in all tested subject groups. However, TCS reductions were not significantly different in OHT, preperimetric, and perimetric glaucoma compared to normals, suggesting that the neuronal or molecular mechanisms generating this adaptation are not affected by glaucoma or compensated in any way. Cellular temporal contrast adaptation prevents saturation at high-contrast stimuli and ensures best eye adjustment to the natural environment, characterised by quickly alternating contrast stimuli $[22,40]$. What mechanisms underlie this type of adaptation? Several studies postulate that temporal contrast adaptation refers mainly to synaptic transmission from bipolar cells to RGCs. There are indications that excitatory synaptic transmission is decreased when adaptation occurs [13, 15, 41, 42]. Interestingly, two different cellular adaptation effects were found: It could be shown that not all neuronal cells in the retina are desensitised after temporal contrast adaptation - a second pool was sensitised [43, 44]. Different measurements of spike activity of RGCs showed that overall rates of uniformly adapted cell populations are lower than a mixed pool of adapted and sensitised neurons [43]. This may be an explanation for the greater TCS reduction after single pre-adaptation than after pre- and re-adaptations at $25 \mathrm{~Hz}$. One RGC population could potentially be adapted resulting in a TCS reduction, whereas a second ganglion cell group could be sensitised. Considering this, one-time adaptation causes a single effect on sensitisation of RGCs whereas re-adaptations could potentially lead to a preponderance of sensitisation of RGC - possibly by quantitative preponderance of the sensitised RGC over time.

Also, the different effects of single pre-adaptation and repeated pre- and re-adaptations could depend on the distinct procedures measuring TCSs: TCS after single pre-adaptation showed a continuous contrast increase over time, whereas TCS after pre- and re-adaptations was measured at different changes of increasing and decreasing test stimuli. Therefore, both strategies might not be directly comparable.

\section{CONCLUSION}

TCS, correlating well with standard perimetric and morphologic parameters, seems to be affected in perimetric glaucoma. Additional adaptation resulted in an overall decrease of TCS. Measurements of TCS using the Erlangen Flicker Test indicate their potential role as a progression parameter in advanced glaucoma when perimetric diagnosis is limited.

\section{REFERENCES}

1. Hohberger B, Rössler CW, Jünemann AGM, Horn FK, Kremers J. Frequency dependency of temporal contrast adaptation in normal subjects. Vis Res 2011; 51: 1312-1317.

2. Korth M, Horn F, Martus P. Quick, Simple Ganzfeld Flicker Test in Glaucoma Diagnosis. Klin Monbl Augenheilkd 1993; 203: 99-103.

3. Korth MJ, Jünemann AMG, Horn FK et al. Synopsis of different sensory examinations in early glaucoma diagnosis. Klin Monbl Augenheilkd 2000; 216: 360-368.

4. Bach M, Wesemann W, Kolling G, Bühren J, Krastel H, Schiefer U. Photopic contrast sensitivity. Local contrast perception. Ophthalmologe 2008; 105: 46-59.

5. Horn FK, Link B, Dehne K, Lämmer R, Jünemann AG. Flicker provocation with LED full-field stimulation in normals and glaucoma patients. Ophthalmologe 2006; 103: 866-872.

6. Horn FK, Korth M, Martus P. Quick full-field flicker test in glaucoma diagnosis: correlations with perimetry and papillometry. J Glaucoma 1994; 3: 206-213.

7. Horn FK, Velten IM, Jünemann A, Korth M. The full-field flicker test in glaucomas: influence of intraocular pressure and pattern of visual field losses. Graefes Arch Clin Exp Ophthalmol 1999; 237: 621-628.

8. Korth M, Horn F, Storck B, Jonas JB. Spatial and spatiotemporal contrast sensitivity of normal and glaucoma eyes. Graefes Arch Clin Exp Ophthalmol 1989; 227: 428-435.

9. Nguyen NX, Horn FK, Seitz B et al. Temporal contrast sensitivity using full-field flicker test (Erlangen flicker test) in patients after penetrating keratoplasty. Graefes Arch Clin Exp Ophthalmol 2002; 240: 443-447.

10. Lee BB, Pokorny J, Smith VC, Martin PR, Valberg A. Luminance and chromatic modulation sensitivity of macaque ganglion cells and human observers. J Opt Soc Am A 1990; 7: 2223-2236.

11. Sclar G, Maunsell JHR, Lennie P. Coding of image contrast in central visual pathways of the macaque monkey. Vis Res 1990; 30: 1-10. 
12. Solomon SG, Peirce JW, Dhruv NT, Lennie P. Profound contrast adaptation early in the visual pathway. Neuron 2004; 42: 155-162.

13. Baccus $S A$, Meister M. Fast and slow contrast adaptation in retinal circuity. Neuron 2002; 36: 909-919.

14. Chander D, Chichilnisky EJ. Adaptation to temporal contrast in primate and salamander retina. J Neurosci 2001; 21: 9904-9916.

15. Smirnakis SM, Berry MJ, Warland DK, Bialek W, Meister M. Adaptation of retinal processing to image contrast and spatial scale. Nature 1997; 386: 69-73.

16. Ibbotson MR. Contrast and temporal frequency-related adaptation in the pretectal nucleus of the optic tract. J Neurophysiol 2005; 94: 136-146.

17. Maffei L, Fiorentini $A, B$ Bisti $S$. Neural correlate of perceptual adaptation to gratings. Science 1973; 182: 1036-1038.

18. Movshon JA, Lennie P. Pattern-selective adaptation in visual cortical neurones. Nature 1979; 278: 850-852.

19. Ohzawa I, Sclar G, Freeman RD. Contrast gain control in the cat's visual system. J Neurophysiol 1985; 54: 651-667.

20. Pasley BN, Mayes LC, Schultz RT. Subcortical discrimination of unperceived objects during binocular rivalry. Neuron 2004; 42: 163-172.

21. Blakemore C, Campbell FW. On the existence of neurones in the human visual system selectively sensitive to the orientation and size of retinal images. J Physiol 1969; 203: 237-260.

22. Sclar G, Lennie P, DePriest DD. Contrast adaptation in striate cortex of macaque. Vis Res 1989; 29: 747-755.

23. Cass $\mathrm{J}$, Alais $D$. Evidence for two interacting temporal channels in human visual processing. Vis Res 2006; 46: 2859-2868.

24. Mandler MB, Makous W. A three channel model of temporal frequency perception. Vis Res 1984; 24: 1881-1887.

25. Breton ME, Wilson TW, Wilson R, Spaeth GL, Krupin T. Temporal contrast sensitivity loss in primary open-angle glaucoma and glaucoma suspects. Invest Ophthalmol Vis Sci 1991; 32: 2931-2941.

26. Cursiefen $C$, Horn $F$, Jünemann AGM, Korth M. Reduced recovery of temporal contrast sensitivity after flicker stress in patients with glaucoma. J Glaucoma 2000; 9: 296-302.

27. Chylack LT Jr, Wolfe JK, Singer DM et al. The Lens Opacities Classification System III. Arch Ophthalmol 1993; 111: 831-836.

28. Jonas JB, Gusek GC, Naumann GOH. Optic disc morphometry in chronic primary open-angle glaucoma. I. Morphometric intrapapillary characteristics. Graefes Arch Clin Exp Ophthalmol 1988; 226: 522-530.

29. Jonas JB, Gusek GC, Naumann GOH. Qualitative morphologic characteristics in normal and glaucomatous eyes. Klin Monbl Augenheilkd 1988; 193: 481-488.
30. Johnson CA. Selective versus nonselective losses in glaucoma. J Glaucoma 1994; 3 (Suppl. 1): S32-S44.

31. Atkin A, Bodis-Wollner I, Wolkstein M, Moss A, Podos SM. Abnormalities of central contrast sensitivity in glaucoma. Am J Ophthalmol 1979; 88: 205-211.

32. Tyler CW. Specific deficits of flicker sensitivity in glaucoma and ocular hypertension. Invest Ophthalmol Vis Sci 1981; 20: 204-212.

33. Tyler CW. Two processes control variations in flicker sensitivity over the life span. J Opt Soc Am A 1989; 6: 481-490.

34. Velten IM, Korth M, Horn FK, Budde WM. Temporal contrast sensitivity with peripheral and central stimulation in glaucoma diagnosis. $\mathrm{Br} \mathrm{J}$ Ophthalmol 1999; 83: 199-205.

35. Horn F, Martus P, Korth M. Comparison of temporal and spatiotemporal contrast-sensitivity tests in normal subjects and glaucoma patients. Ger J Ophthalmol 1995; 4: 97-102.

36. Horn FK, Jonas JB, Korth M, Jünemann A, Gründler $A$. The full-field flicker test in early diagnosis of chronic open-angle glaucoma. Am J Ophthalmol 1997; 123: 313-319.

37. Jünemann AGM, Horn FK, Martus P, Korth M. The full-field temporal contrast sensitivity test for glaucoma: influence of cataract. Graefe's Arch Clin Exp Ophthalmol 2000; 238: 427-432.

38. Austin MW, O'Brian CJ, Wishart PK. Flicker perimetry using a luminance threshold strategy at frequencies from $5-25 \mathrm{~Hz}$ in glaucoma, ocular hypertension and normal controls. Curr Eye Res 1994; 13: 717-723.

39. Holopigian K, Seiple W, Mayron C, Koty R, Lorenzo M. electrophysiological and psychophysical flicker sensitivity in patients with primary open-angle glaucoma and ocular hypertension. Invest Ophthalmol Vis Sci 1990; 31: 1863-1868.

40. Rieke F. Temporal contrast adaptation in salamander bipolar cells. J Neurosci 2001; 21: 9445-9454.

41. Beaudoin DL, Borghuis BG, Demb JB. Cellular basis for contrast gain control over the receptive field center of mammalian retinal ganglion cells. J Neurosci 2007; 27: 2636-2645.

42. Kim KJ, Rieke F. Temporal contrast adaptation in the input and output signals of salamander retinal ganglion cells. J Neurosci 2001; 21: 287-299.

43. Kastner DB, Baccus SA. Coordinated dynamic encoding in the retina using opposing forms of plasticity. Nat Neurosci 2011; 14: 1317-1322.

44. Nikolaev A, Leung KM, Odermatt B, Lagnado L. Synaptic mechanisms of adaptation and sensitization in the retina. Nat Neurosci 2013; 16: 934-941. 